\title{
COLONIALISMO DO SABER E SUAS IMPLICAÇÕES PARA A APLICAÇÃO DA LEI № 10.639/2003 NAS ESCOLAS PÚBLICAS
}

\author{
Joyce de Sena Lima ${ }^{1}$ \\ Rosalvo Nobre Carneiro²
}

\begin{abstract}
RESUMO
A partir dos aportes teóricos do colonialismo, da colonialidade e da colonização do "mundo do sistema" sobre o "mundo da vida", os cruzamentos de olhares aqui pensados operam como fundamentos para problematizar as implicações do discurso colonizador no processo de execução da lei no 10.639/2003. O presente trabalho, de cunho bibliográfico, embasa-se em Anibal Quijano, Sandra Petit e Jürgen Habermas, buscando contribuir à análise da necessidade de professores e professoras apreender o reconhecimento étnico como forma de desconstrução de saberes eurocentrados para a construção de novos paradigmas educacionais inclusivos. Neste sentido, busca-se refletir sobre o ensino das relações étnico-raciais na educação básica e os desafios epistemológicos e práticos de estabelecimento da referida lei. Da mesma forma, pretende-se pensar sobre as possibilidades de enegrecer os planos de aulas dos professores. Assim, o texto traduz-se em inquietações sobre o direito dos educandos de conhecer uma África desestigmatizada e valorizada. Compreendemos, então, que os argumentos discursivos coloniais foram prerrogativas para a exploração do trabalho, a criação de estereótipos e a depreciação da imagem e da autoestima da população negra, bem como se configuram como obstáculos a saberes sistematizados referentes à história desta população na escola.
\end{abstract}

Palavras-chave: Colonialismo do saber. Mundo da vida. Lei no 10.639/2003. Ensino das relações étnico-raciais.

\section{COLONIALISM OF KNOWLEDGE AND ITS IMPLICATIONS FOR THE APPLICATION} OF LAW N. 10.639/2003 IN PUBLIC SCHOOLS

\section{ABSTRACT}

From the theoretical contributions on colonialism, coloniality, and colonization of the "life-world" by the "system-world," the crosses of looks discussed here operate as the basis for problematizing the implications of the colonizing discourse during the process of implementing the law No. 10639/2003.The present theoretical work is based on Anibal Quijano, Sandra Petit and Jürgen Habermas, analyzing the need for teachers to learn the ethnic recognition as a form of deconstruction of Eurocentred knowledge, aiming at the construction of new inclusive educational paradigms. In this sense, we seek to reflect on the teaching of ethnic-racial relations in basic education and the epistemological and practical challenges of implementing the aforementioned law are pondered. Likewise, the possibilities of blackening teachers' lesson plans are discussed. Thus, the text addresses concerns about the right of learners to know a non-stigmatized and valued Africa. In conclusion, we understand that colonial discursive arguments were prerogatives for the exploitation of work, the creation of stereotypes and the depreciation of the image and the self-esteem of the black population, as well as being obstacles to the implantation of systematized knowledge regarding the history of this population in the school.

Keywords: Colonialism of knowledge. Life-world. Law No. 10.639/2003. Teaching of ethnic-racial relations.

RECEBIDO EM: 20/2/2019

ACEITO EM: 19/4/2019

\footnotetext{
${ }^{1}$ Geógrafa formada pela Universidade do Estado do Ceará - Uece (2013). Mestranda do Programa de Pós-Graduação em Ensino (PPGE) da Universidade do Estado do Rio Grande do Norte - Uern. joycedesena@gmail.com.

${ }^{2}$ Geógrafo formado pela Universidade Estadual da Paraíba - UEPB (2001). Doutor em Geografia pela Universidade Federal do Pernambuco - Ufpe (2011). Docente do Programa de Pós-Graduação em Ensino (PPGE) da Universidade do Estado do Rio Grande do Norte - Uern. rosalvonobre@uenr.br
} 
Os saberes coloniais fazem parte do estado de coisas existentes, portanto conformam a totalidade dos fatos do nosso mundo da vida cotidiano. Tais saberes, suas origens, desenvolvimento e compreensão atuais, no entanto, estão diretamente relacionados à falta de reconhecimento das contribuições históricas e culturais dos povos africanos e, também, ao que nos foi negado, nesses aparatos histórico-culturais, ao longo do tempo durante o processo de formação territorial do Brasil.

Manuel Correia de Andrade (1996) alertara geógrafos e historiadores para a crescente busca por conhecimentos, no Brasil, sobre o continente africano na década de 90, movimento atrelado à consciência de uma africanidade na cultura brasileira. Assim, a ausência de um sentimento de pertencimento étnico ao Brasil, que apenas tardiamente se constrói enquanto sentido de nação, limitou-se o olhar do "sujeito" brasileiro, ou, ainda, ao não vislumbramento de possibilidades de novas construções teóricas e entendimento da diversidade social.

Por vezes eurocentrado, o saber colonial e, ao mesmo tempo, colonizado, exige, nos dias atuais, avanços e mudanças no âmbito do mundo da educação, particularmente com abordagens voltadas para o ensino das relações étnico-raciais e à execução da lei $n=10.639 / 2003$ na realidade escolar. Neste contexto, dispõe a referida lei:

Art. 26-A. Nos estabelecimentos de ensino fundamental e médio, oficiais e particulares, torna-se obrigatório o ensino sobre História e Cultura Afro-Brasileira.

$\S 1^{\circ} \mathrm{O}$ conteúdo programático a que se refere o caput deste artigo incluirá o estudo da História da África e dos Africanos, a luta dos negros no Brasil, a cultura negra brasileira e o negro na formação da sociedade nacional, resgatando a contribuição do povo negro nas áreas social, econômica e política pertinentes à História do Brasil.

$\S 2^{\circ}$ Os conteúdos referentes à História e Cultura Afro-Brasileiras serão ministrados no âmbito de todo currículo escolar, em especial nas áreas de Educação Artística e de Licenciatura e História Brasileira.

O dispositivo legal chama atenção e merece cuidado, pois apresenta uma contradição ao afirmar que a História e a Cultura Afro-Brasileiras devem ser ministradas no âmbito de todo o currículo escolar e, ao mesmo tempo, destaca este ensino como prerrogativa especial de algumas áreas como responsáveis por ministrá-la. Neste particular, cabe questionar o papel da Geografia como disciplina escolar e seu olhar sobre as questões da Geografia e Cultura Afro-Brasileiras no contexto de formação do raciocínio geográfico e da aprendizagem espacial.

Nessa "geografia das cores" - branca, preta, amarela, parda ou indígena - os dados do Instituto Brasileiro de Geografia e Estatística (IBGE) revelam redução da população branca e aumento dos que se declaram pardos e pretos da década de 2010 para cá. Em 2016, o percentual dos brancos na população do país foi de $44,2 \%$, dos pardos $46,7 \%$ e a dos pretos $8,2 \%$ (SARAIVA, 2017).

Neste cenário, completou-se, em 2018, 15 anos de existência da lei no 10.639/2003, que regulamenta a inclusão no currículo oficial da rede de ensino pública e privada a obrigatoriedade da temática "História e Cultura Afro-Brasileira". Muitas foram as críticas levantadas por sua dificuldade de introdução no âmbito da escola, críticas atreladas, principalmente, à questão da formação docente. Ao mesmo tempo, 
reconhece-se avanços no que diz respeito às políticas educacionais por fomentarem o caráter plural da sociedade brasileira por meio da legislação, conquista advinda do movimento negro após tantas tentativas de oportunizar acesso à história e cultura africanas no âmbito da educação formal no Brasil. Para além desse debate quanto às críticas e avanços, busca-se perceber novas possibilidades de alcance do cumprimento da referida lei, o que implica na desconstrução de saberes eurocentrados, na visibilidade de novas culturas e, sobretudo, no reconhecimento de si e do outro.

O presente texto traz subsídios teóricos que operam como fundamentos para problematizar as implicações do discurso colonizador no processo de instituição da lei no $10.639 / 2003$, das formas como os argumentos da colonização foram prerrogativas para a exploração do trabalho, a criação de estereótipos e a depreciação da imagem e da autoestima da população negra, bem como dos obstáculos na execução de saberes sistematizados referentes à sua história.

Adotou-se o método bibliográfico de pesquisa embasado em concepções que pautam o paradigma contra hegemônico de decolonização do saber. Dessa forma, dentre os autores utilizados como referência temos Anibal Quijano (2005) e Catherine Walsh (2009), cujas visões podem ser ampliadas no contexto da racionalidade comunicativa de Jüngen Habermas (2012a, 2012 b), como forma de possibilitar o reconhecimento do outro e o entendimento com o outro como condição para a descolonização do mundo da vida. Neste contexto de reflexões, caberá também compreender o colonialismo do saber numa reflexão acerca das possibilidades de emancipar nossas práticas docentes e de enegrecer nossos planos de aula.

\section{DA COLONIALIDADE DO SABER}

Primeiramente cabe discutirmos alguns termos centrais, sendo isto condição e necessidade de compreensão das articulações entre a teoria do agir comunicativo e a teoria da pedagogia decolonial. Assim, destacam-se a colonização e a descolonização, o colonialismo, a colonialidade e a decolonialidade, na tentativa de elucidar as bases que sustentam a hegemonia epistemológica eurocêntrica e apresentar possibilidades de emancipação numa perspectiva de valorização e compreensão da diversidade epistêmica, com sentido inclusivo, reconhecendo, deste modo, a multiplicidade de saberes.

Os conceitos de colonialismo e colonialidade relacionam-se e aparecem juntos, uma vez que dizem respeito à forma de dominação do poder colonial sobre povos, nações e seus saberes multiculturais. A colonialidade, apesar de mais recente que o colonialismo, apresenta maior profundidade, pois se relaciona às formas modernas de dominação pós-colonial, após séculos de escravidão, e manifesta-se por meio das bases de um racismo estrutural que subalterna saberes, formas de trabalho e falas que atingem as raízes mais profundas de um povo e que sobrevivem apesar da descolonização das colônias (QUIJANO, 2005).

O modo como interpretamos o colonialismo na pedagogia decolonial o insere num modelo à vista da geopolítica, estando associado ao controle territorial à moda dos geógrafos, ou como uma negação da soberania popular no caso dos cientistas políticos. Logo, este modo de definir o colonialismo difere da concepção de Jürgen Habermas de colonização como processo de racionalização social. 
A colonialidade depreende-se dos seus postulados como uma forma de dominação sobre as instituições sociais, incluindo os modos de conhecer e as formas de relações intersubjetivas, que passam a se articular mediadas por meios não linguísticos, como o dinheiro e o poder no modo capitalista de produção. Neste sentido, o que se chama colonialidade e decolonialidade configura-se por aproximações teórico-conceituais como processos de colonização e descolonização do mundo da vida em Jürgen Habermas.

Neste ponto, cabe destacar que a teoria da modernidade em Habermas inclui os processos de modernização societária e modernização cultural, associados respectivamente ao mundo do sistema e ao mundo da vida, enquanto sociedade em sentido amplo. Freitag (2005) resume em quatro tipos as transformações ocorridas no tempo, incluindo a diferenciação (visões descentradas de mundo, divisões de tarefas econômicas e políticas), racionalização (transformação das instituições consoante à racionalidade instrumental), autonomização (o desprendimento relativo de um subsistema, como a ciência em relação ao mundo da vida) e dissociação (naturalização da economia e do poder ante os processos sociais da vida cotidiana).

Assim, com a racionalização e a dissociação entre o sistema e o mundo da vida, vislumbra-se a colonização deste por aquele. Ou seja, este processo refere-se à penetração da racionalidade instrumental nas esferas das instituições culturais da sociedade, por meio dos mecanismos de integração social como o "dinheiro" e o "poder". Como alerta Freitag (2005), porém, isto não significa que estas instituições ou, em outras palavras, as pessoas e os grupos que as formam, deixem de funcionar segundo os princípios básicos de verdade, moralidade e expressividade mediante a ação comunicativa empregada no dia a dia.

Nas palavras de Habermas (2012b), misturando análise fática e metáfora temporal, depreende-se o sentido de colonização do mundo da vida ao afirmar:

Pois, no instante em que os imperativos dos subsistemas autonomizados conseguem levantar seu véu ideológico eles se infiltram no mundo da vida a partir de fora - como senhores coloniais que se introduzem numa sociedade tribal-, impondo a assimilação; ademais, as perspectivas difusas da cultura autóctone não se deixam coordenar num ponto que permita entender, a partir da periferia, o jogo desenvolvido pelas metrópoles e pelo mercado mundial (HABERMAS, 2012b, p. 639, grifo nosso).

A dissociação entre sistema e "mundo vital" nas sociedades modernas, com a penetração dos imperativos sistêmicos e a racionalização do mundo da vida, provoca implicações sobre o "esclarecimento" ao transformar em razão técnica formalista, em "cultura de experts", sem substância ética, o que pode ser enganadora das massas. Essas são as duas "condições necessárias" para o processo de colonização, segundo comentários de Siebeneichler (2003) sobre a teoria habermasiana, ao qual ele acrescenta uma terceira "condição suficiente", expressa na fragmentação do mundo da vida, em seu esvaziamento cultural e coisificação, na perda de sentido e de liberdade e na subsunção da esfera pública e privada. 
Por isso, a profundidade da colonialidade envolve as bases epistêmicas excluídas ou inferiorizadas que estão expressas em textos didáticos, na cultura, nas relações entre os sujeitos, nas veracidades científicas, na autoimagem dos povos, no sentido do que é comum, do que é normal, além de vários outros sentidos atribuídos à modernidade atrelada à ideia de raça.

A ideia de raça, aprofundada como uma "categoria mental da modernidade", relaciona-se às diferenças fenotípicas entre conquistadores e conquistados, diferenciando-os "biologicamente" em diferentes grupos. As relações sociais fundadas nessa ideia produziram na América novas identidades sociais (negros, índios, mestiços) e redefiniram outras; assim, as configurações das relações sociais foram configurando-se em identidades, à medida que essas foram associadas às hierarquias, lugares e papéis sociais correspondentes (QUIJANO, 2005).

Por vezes, a valorização de saberes eurocêntricos como uma perspectiva hegemônica de dominação do conhecimento, implica formação estrutural de uma base epistemológica excludente que nega o outro e sua cultura. Isso se dá por uma articulação histórica entre raças como um instrumento de classificação e controle social e o desenvolvimento do capitalismo mundial (moderno, colonial, eurocêntrico). O eurocentrismo como perspectiva de dominação capaz de categorizar superiores e inferiores, humano e desumano, racional e irracional, estabelece uma ordem de apropriação de saberes que negativa ou anula outros, o que se pode associar à colonialidade do saber (WALSH, 2009).

Com a base epistêmica focalizada geograficamente na Europa, desvalorizando as epistemologias africanas, a geopolítica do conhecimento é uma estratégia da modernidade europeia que reafirmou suas teorias e seus conhecimentos como verdades absolutas que Quijano (2005) trata como "colonialidade do poder", ou seja, uma forma particular de racionalidade que se torna hegemônica sobre todas as demais formas de conhecimento.

Assim, por exemplo, o conceito de "colonialidade do poder" de Quijano, como explicam Oliveira e Candau (2010), faz referência direta à ocidentalização do mundo, especialmente sobre o mundo do imaginário, portanto, da sociedade e dos indivíduos, ao construir subjetividades subalternizadas, a exemplo das raças e dos seus saberes, e reprimir seus "mundos simbólicos". Consoante Habermas (2012a), os mundos da vida são compartilhados intersubjetivamente e simbolicamente estruturados em tradições culturais dos povos, em normas constitutivas dos grupos sociais e em processos de socialização dos indivíduos pertencentes a estes povos e a estes grupos.

Essa construção de pensamento acaba por dominar não somente os europeus, mas todo o mundo, e se apresenta em um inconsciente imaginário capaz de subalternizar outras formas de conhecimento advindas, por exemplo, da África. Essa dominação de conhecimento, conhecida como eurocentrismo, torna-se também uma perspectiva cognitiva do conjunto daqueles educados por sua hegemonia. Nessa direção, explicitam Bernadino-Costa e Grosfoguel (2016): 
A partir do século XVI iniciou-se, portanto, a formação do eurocentrismo ou, como nomeia Coronil (1996), do ocidentalismo, entendido como o imaginário dominante do mundo moderno/colonial que permitiu legitimar a dominação e a exploração imperial. Com base nesse imaginário, outro (sem religião certa, sem escrita, sem história, sem desenvolvimento, sem democracia) foi visto como atrasado em relação à Europa. Sob esse outro é que se exerceu o "mito da modernidade" em que a civilização moderna se autodescreveu como a mais desenvolvida e superior e, por isso, com a obrigação moral de desenvolver os primitivos, a despeito da vontade daqueles que são nomeados como primitivos e atrasados (Dussel, 2005). Esse imaginário dominante esteve presente nos discursos coloniais e, posteriormente, na constituição das humanidades e das ciências sociais. Essas não somente descreveram um mundo, como o "inventaram" ao efetuarem as classificações moderno/coloniais. Ao lado desse sistema de classificações dos povos do mundo houve também um processo de dissimulação, esquecimento e silenciamento de outras formas de conhecimento que dinamizavam outros povos e sociedades (p. 17).

A classificação moderno/colonial ou modernidade-colonialidade contribui com a ideia de exclusão, uma vez que nega e subordina o outro dentro do sistema mundo capitalista, que foi estrategicamente guiado por relações distorcidas de poder econômico e político. Neste cenário, o entendimento sempre é possível, defendendo-se, no entanto, as relações hierárquicas próprias do sistema de poder, que interferem nas relações horizontais dialógicas. Deste modo, os sujeitos, ao invés de se emanciparem, estariam continuamente subordinados à dominação de uns sobre os outros. Esta coisificação dos sujeitos, em razão de interesses egoístas, é própria dos modos de agir estratégicos, atos de fala que visam tanto a influenciar o comportamento do outro quanto à obtenção de "consenso" por via da violência simbólica ou física (HABERMAS, 2009).

As imposições de relações mediadas pelos meios não linguísticos, como o dinheiro e o poder, do mundo do sistema e sobre as pessoas, os grupos e a sociedade como um todo organizado simbolicamente em seus mundos da vida, resulta do processo de colonização, com desdobramentos em nosso inconsciente na forma de domínio e controle dos pensamentos e do comportamento humano. Essas imposições racionais, estrategicamente fabricadas pelo colonizador, foram uma forma violenta de anular as potencialidades culturais africanas, daí a necessidade de estar vigilantes quanto aos discursos, às falas e às ações, ou, ainda, atentarmos às ações de fala, para não anularmos o outro diante da falta de reconhecimento intersubjetivo de sua própria história.

A idealização de uma razão que possibilite a descolonização do mundo da vida ante os imperativos do mundo sistêmico, deve ser buscada na perspectiva da construção e uso do conhecimento, na forma de uma racionalidade comunicativa, dialógica. Seria, portanto, uma razão capaz de compreender e reconhecer o potencial emancipador das relações eu-tu por meio do entendimento do eu com o outro. $O$ entendimento representa, neste caso, a própria tomada de consciência e a ação que permitem apreender o que é imposto por relações assimétricas em um mundo de poder, bem como possibilita nos posicionarmos em relação a esse mundo de poder nas esferas da cultura, das normas sociais e da formação da personalidade. 
Pensando nisso, Carneiro e Sá (2007) tem defendido o "espaço público comunicativo" como capaz de promover esta descolonização/emancipação, em que a sua produção e reprodução orientadas para a cidadania se configuram por um sistema de objetos enquanto formas, com funções comunicativamente construídas por meio de um sistema de ações guiadas pelos processos de obtenção do entendimento mútuo e geradores do consenso racionalmente motivado sobre as questões estruturantes de seus mundos da vida. Vem daí, então, a relevância e a necessidade de situarmos essas discussões no horizonte do mundo da vida escolar, ao mesmo tempo em que o relacionamos aos regulamentos legais da sociedade brasileira sobre a História e a Cultura Afro-Brasileiras.

\section{A LEI № 10.639/2003 E SEUS DESAFIOS DE EFETIVAÇÃO}

Considerada um avanço significativo na educação brasileira como possibilidade de se repensar as abordagens eurocêntricas, a lei no 10.639 , promulgada em janeiro de 2003, contribui para uma reflexão crítica a respeito do direito do/a educando/a conhecer a História e a Cultura Afro-Brasileiras e estes integrarem aspectos e contextos de sua realidade histórica. Os impasses da sua não efetivação na maioria das escolas públicas ainda vigoram, mas cabe refletir de que maneira esta lei vem sendo executada em sala de aula.

Nesse contexto, chegamos às seguintes indagações: a lei $n=10.639 / 2003$ está sendo efetivamente posta em prática nas escolas? Ou aparece apenas em uma semana, fora da rotina escolar, para comemorar o Dia da Consciência Negra? Cumprem-se, quando é oferecido pela Secretaria de Educação, uma ou duas semanas de formação para os professores sobre as relações étnico-raciais? Ou, ainda, aparecem apenas com a elaboração de projetos nos dias 13 de maio nas áreas de ciências humanas? Pensamos que, se apresentado desta forma, o ensino das relações étnico-raciais converte-se em folclore, e, por isso, logo carece aproximar-se os/as alunos/as de uma realidade e história que Ihes pertence e, como tal, precisa ser valorizada e entendida cotidianamente.

Para tanto, faz-se necessário pensar uma nova construção epistemológica que valorize o saber dos povos tradicionais por meio da oralidade e que perceba e reconheça o saber espiritual das comunidades indígenas, em que a ancestralidade seja reconhecida como signo de resistência afrodescendente, que

[...] protagoniza a construção histórico cultural do negro no Brasil e gesta, ademais, um novo projeto sócio-político fundamentado nos princípios da inclusão social, no respeito às diferenças, na convivência sustentável do Homem com o Meio-Ambiente, no respeito à experiência dos mais velhos, na complementação dos gêneros, na diversidade, na resolução de conflitos, na vida comunitária entres outros. Tributária da experiência tradicional africana, a ancestralidade converte-se em categoria analítica para interpretar as várias esferas da vida do negro brasileiro. Retroalimentada pela tradição, ela é um signo que perpassa as manifestações culturais dos negros no Brasil, esparramando sua dinâmica para qualquer grupo racial que queira assumir os valores africanos. Passa, assim, a configurar-se como uma epistemologia que permite engendrar estruturas sociais capazes de confrontar o modo único de organizar a vida e a produção no mundo contemporâneo (OLIVEIRA, 2009, p. 3). 
Os professores e professoras precisam reconhecer e valorizar os mundos da vida de seus alunos e alunas, isto é, "mundos compartilhados intersubjetivamente" por pessoas, tendo como referência a cultura, os grupos sociais com suas normas e as pessoas de referência para formação de personalidades. Como assinala Habermas (2012a), o mundo da vida forma um contexto de horizontes para os sujeitos socializados e se estrutura pelas tradições culturais, pelas normas socialmente estabelecidas e pela formação das personalidades e identidades dos indivíduos.

Assim, a perspectiva de pertencimento afro remete a uma forma de compartilhamento de um contexto espacial, que é objetivo, intersubjetivo e subjetivo, um mundo da vida particular, captado como parte integrante do todo que é a pessoa vivendo a realidade e as suas percepções construídas na relação com o seu meio, cada vez mais técnico, científico e informacional (SANTOS, 2004). É importante frisar, corroborados em Carneiro e Pinto (2012), que o ensino de Geografia na educação básica no século 21 se relaciona com este meio geográfico, quando estas categorias básicas do fazer docente na atualidade - ciência, técnica e informação - precisam ser abordadas no contexto de articulação entre o mundo vivido e o mundo do sistema pelas interações múltiplas entre eles.

Por isso, ainda consoante Carneiro e Pinto (2012), destaca-se aqui a "densidade comunicacional do espaço", que se relaciona ao uso da linguagem em sua forma orientada para o entendimento mútuo, no que diz respeito às ações pedagógicas do professor de Geografia ao buscar relacionar como este dado constitutivo do mundo vivido cotidiano dos alunos se relaciona com as densidades técnica, científica e informacional do espaço. Assim sendo, chama-se a atenção diante de um "apagamento histórico" da contribuição científica e da pedagogia relativa à contribuição cultural de raiz africana (PETIT, 2015).

Petit (2015) retrata a existência de um "inconsciente coletivo" que abafa e silencia a referência ao negro ou que mantém essa referência estigmatizada. Esse inconsciente coletivo que negativa e desaprova ciências africanas relacionadas à espiritualidade, à física, à matemática, por exemplo, foi construído pelo poder estratégico de dominação colonial de forma a desvalorizar a ciência africana. Relaciona-se, também, à desvalorização dos saberes sociais próprios de mundos da vida particulares, em uma sociedade cuja ciência virou ideologia e meio de ocultação do controle (HABERMAS, 2009), invalidando, assim, verdades construídas no contexto de culturas tradicionais.

Por isso, práticas racistas são percebidas dentro da escola como reflexo das relações distorcidas e estabelecidas pela sociedade, na forma de "brincadeiras preconceituosas" por parte de outros atores sociais, alunos, alunas ou professores e professoras. Como reflexo social, essas "questões moral-práticas relevantes", isto é, toda questão passível de ser resolvida pelo consenso, no dizer de Habermas (1989), requer atenção da escola e dos seus sujeitos educacionais.

Espacialmente deve-se atentar para isso, pois, sendo reflexo da sociedade, essas práticas, enquanto atos de falo linguisticamente estruturados, resultam e condicionam processos de segregação e discriminação espacial entre bairros onde as histórias de 
construção dos territórios periféricos são marcadas pela marginalização e estigmatização como "territórios negros". Este contexto não deixa, assim, de se fazer presente no espaço/mundo da vida escolar.

Se vivemos em uma sociedade orientada para a obtenção de consenso sobre tal questão, que é, por sua vez, moralmente relevante à educação, é a forma de transformação social objetivando a formação para a cidadania que tem a capacidade de ofertar às pessoas em formação a possibilidade de desconstruir imagens sociais introjetadas pela cultura racista de superioridade entre grupos humanos (MUNANGA, 2005). Assim, a racionalização do mundo da vida não ocorre apenas a partir de cima, dos processos de colonização, mas também a partir de baixo, da quebra de entraves ao entendimento (HABERMAS, 2009), portanto da própria reconstrução das imagens de mundo e dos saberes socialmente reconhecidos como válidos no tempo histórico e no espaço social.

Nesse contexto de perpetuação do racismo, a tentativa de execução da lei no 10.639/2003 tornou-se um grande desafio nas escolas. O "racismo estrutural" no Brasil, baseado num sistema meritocrático, agrava as desigualdades. Ao mesmo tempo, há uma demanda por educação advindo da comunidade afro-brasileira, que evidencia a necessidade de reconhecimento expresso na valorização da diversidade e na ressignificação de termos como negro e raça, bem como pela superação do etnocentrismo e da interpretação eurocêntrica da realidade brasileira, da África e dos afro-brasileiros (OLIVEIRA; CANDAU, 2010).

Recomendava o geógrafo negro Milton Santos (2002), nos anos idos de 2000, que esta questão escorregadia fosse pensada em termos de "ser negro no Brasil, o que é?", um objeto de olhares vesgos e ambíguos, pois já vislumbrava uma substituição no debate em torno de questões sociais e morais por "referências ao dicionário" e às discussões semânticas sobre preconceito, discriminação e racismo.

Construir uma perspectiva de entendimento do diverso promoveria, certamente, o resgate da ancestralidade afro dos alunos e alunas e professores e professoras. Para tanto, almeja-se uma forma de diálogo aberto e facilitador para execução da lei no 10.639/2003 na escola pública. Passa-se, assim, pela possibilidade de aproximação e descoberta das suas raízes africanas no contexto histórico e geográfico das áreas periféricas atreladas à construção do conhecimento como processo que, partindo do ensinar e do aprender, aparece como momentos menores do processo de reconhecimento (FREIRE, 2015).

Nesse sentido, é importante que alunos e alunas possam se reconhecer enquanto sujeitos capazes de transformar seus espaços e que os educadores estejam dispostos a aprender a aprender, numa perspectiva de descolonizar-se do saber escravizador de domínio de valorização eurocêntrica que negativa a história africana. A "descolonialidade representa uma estratégia de libertação", pautada na reconstrução do ser, do poder e do saber (OLIVEIRA; CANDAU, 2010).

A disposição dos professores e professoras é levantada no sentido de apropriar-se de sua história e isso é, muitas vezes, conflituoso, pois requer resgatar uma identidade própria do ser, de seus laços familiares, de sua forma de se ver no mundo, de ter de res- 
gatar em si questões do passado que refletem em suas ações do presente. Muitas vezes, esse resgate traz consigo simbologias do concreto por vezes esquecidas ou negadas durante o tempo.

Africanidades brasileiras são conjuntos de raízes e culturas trazidas da África durante o processo de escravidão que se fazem presentes na nossa formação cultural, muitas vezes expressas, praticadas ou vivenciadas no cotidiano de negros/as e de não negros/as. "Os marcadores de africanidades ajudam a aproximar pessoas, pois eles identificam as africanidades como elementos presentes no processo civilizatório que afetam negros e não negros, opondo-se aos modelos que tentam subalternizar nossos corpos afros ancestrais" (PETTIT; FARIAS, 2015).

Dentre estes marcadores, chamamos atenção para a "história do lugar de pertencimento", resgatando as simbologias territoriais identificadas por locais afromarcados, que fazem parte da história individual, que é, por vezes, negativada. As pessoas negras, referências da família e da comunidade, também são apontadas como marcadores de africanidade. Essas referências, além de serem identificadas, devem ser valorizadas, à medida que trazem consigo ensinamentos herdados e que podem ser repassados para as gerações seguintes como forma de reconhecimento da negritude presente dentro da comunidade, proporcionando a valorização dos mais velhos (senhoridade) enquanto atitude fundamental na perpetuação da cultura de um lugar.

As práticas de saúde e de cura, utilizando ervas medicinais ou rituais de cura, como benzer para afastar uma dor de cabeça ou dor intestinal, são práticas presentes no cotidiano e que, usualmente, não são valorizadas, mesmo que se recorra a elas frequentemente, seja um chá, um banho de plantas medicinais, seja inalação de ervas, demonstrando a relação cíclica com a natureza, evidenciada na cultura africana. Nessa conexão histórico/cultural com a cultura africana, os territórios afromarcados - como os espaços de terreiros de umbanda e candomblé, comunidades quilombolas, lugares místicos e simbólicos relacionados à espiritualidade - expressam o sentido de pertencimento africano referindo-se às formas de conviver e de relações comunitárias, o que contribui para dimensionar o quanto de africanidade está presente nesses locais.

Os marcadores podem ser ampliados e "[...] relacionam-se profundamente com as histórias e as memórias dos sujeitos e de seus antepassados. Cada um deles desperta um sentido ou um sentimento relativo ao nosso pertencimento e às influências da Mãe África no cotidiano, na nossa cultura" (PETTIT; FARIAS, 2015, p. 140). São esses significados que precisam ser valorizados e produzidos numa perspectiva de construção de identidade, dos valores do lar e da segurança afetiva, reconhecendo a ancestralidade dentro da história individual, do contexto vivido, da relação com a natureza e dos laços familiares.

\section{ENEGRECIMENTO DOS PLANOS DE AULA}

Enegrecer nossos planos de aula na educação básica de ensino se constitui uma tarefa desafiante, pois diz respeito ao reconhecimento de si - dos contextos individuais - para se chegar ao alcance do outro. Esse enegrecimento significa evidenciar, nos conteúdos abordados em sala, o que de fato remete à história do continente africano, le- 
vando em consideração sua cultura, a diversidade entre os povos dos vários países desse lugar, a religiosidade, a dança, a música, o estilo, a partilha e a relação com outros povos; enfim, é relacionar fatos sem deixar lacunas.

Neste debate, propriamente pós-colonial, em que se reorganizam as categorias da diferença e da alteridade, refletimos, assim, com Pimenta, Sarmento e Azevedo (2007), sobre o que é ou poderá ser a Geografia no contexto de dinamização das discussões sobre a política de lugar: a política de representação relacionada às profundas transformações nas instâncias sociais de produção das subjetividades. Nesta forma de pensar, particularmente perguntamos sobre a geografia escolar e a educação geográfica - sobre o que são hoje e o que podem vir a ser.

É necessário, então, pensar uma educação voltada para o diálogo, que atue valorizando e ensinando a história contada desde os sujeitos que a vivenciam. A África não pode ser abordada (como acontece em muitas aulas) somente como atribuição às mazelas ou relacionada aos processos de escravidão: sair desse lugar é agenciar uma educação que pensa e promove as relações étnico-raciais, que almeja e busca uma comunidade/sociedade que valoriza e respeita o outro em suas singularidades e diversidade (MACHADO, 2014).

É importante reforçar que o parecer da lei no 10.639/2003, apesar de enfatizar o ensino das relações étnico-raciais nas disciplinas como Educação Artística, Literatura e História do Brasil, evidencia que isso deverá ser desenvolvido no cotidiano escolar e ministrado no âmbito de todo o currículo escolar. Dessa forma, a interdisciplinaridade faz-se fundamental nesse processo, uma vez que requer uma reflexão não somente em torno dos conteúdos e sua integração com outras áreas de conhecimento, mas, também, com a inter-relação entre os sujeitos envolvidos no processo de ensino e aprendizagem: alunos/as e professores/as. Essa troca de conhecimento envolve respeito às verdades relativas a cada disciplina, e a pretensão em aplicá-la na escola perpassa pelo rearranjo dos conteúdos (FAZENDA, 2011).

Respeitar a verdade de cada disciplina está no reconhecimento desta e do outro. A inter-relação entre os sujeitos no cotidiano escolar é uma tarefa que envolve não somente esforços individuais por parte dos professores/as, mas também o seu reconhecimento. Atribuir a responsabilidade do ensino das relações étnico-raciais aos professores da área de ciências humanas, tais como geografia, história, filosofia e sociologia, é uma forma de desrespeitar as epistemologias africanas na medida em que não se reconhece a importância das contribuições dessas nas ciências exatas, na matemática e na linguagem.

Não se trata, portanto, de enxergar o ensino das relações étnico-raciais numa abordagem temática sobre África, africanidades ou negros; trata-se de vivenciar estas relações cotidianamente no ambiente escolar e de valorizar os contextos dos alunos e alunas e sua relação com as africanidades, resgatando a história que nos pertence enquanto afrodescendentes. Isso requer uma análise crítica de cada professor e professora quanto ao que nos foi imposto nos nossos cursos de formação, pois as universidades também negativam o que é atribuído ao negro, à África e ao que herdamos dos nossos antepassados. 
No espaço escolar, os livros didáticos, em sua maioria, não contemplam uma literatura negra; logo, os alunos e alunas não se enxergam nas leituras, pois seus contextos são excluídos dos conteúdos. Muitas vezes a questão da africanidade é trazida quando se abordam questões relacionadas ao racismo, ou quando se aborda o continente africano no viés físico e de localização. Nesse sentido, enegrecer nossas aulas também é romper com estruturas de dominação do saber, já consolidadas em formas de burocratização do poder que alimentam a reprodução do mundo do sistema, numa razão instrumentalizada orientada para fins particulares, eficientes, causais, a partir de intervenções no mundo dos estados de coisas existentes (HABERMAS, 2012a).

Por outro lado, há uma contrarracionalidade, no dizer de Santos (2004), a esta racionalidade hegemônica, instrumental, egocêntrica e egoísta, que adviria da racionalidade dos processos de entendimento mútuo, os quais se medem pelas condições de validade exigidas nos atos de fala e que podem ser resgatadas discursivamente (HABERMAS, 2012a), pretensões de validade implícitas nas ações que são as falas dos sujeitos sociais, conforme verdades (mundo objetivo social), correções normativas (mundo intersubjetivo social) e as veracidades (mundo subjetivo pessoal). Assim, propõe-se o entendimento por meio do uso da linguagem em atos de fala e pelo questionamento e busca de acordo sobre estas pretensões de validade. Por conseguinte, uma educação amparada em contextos de desenvolvimento do agir comunicativo promoveria a compreensão do que é dito pelo interlocutor, o reconhecimento do que é pronunciado por ele e o entendimento com o outro.

Toma-se aqui como exemplo uma suposta aula de geografia na turma do oitavo ano do Ensino Fundamental: as abordagens trazidas no livro didático "Expedições geográficas" (ADAS; ADAS, 2015), no capítulo 1, com o tema "Continentes e os oceanos". O professor poderia não evidenciar a África e até achar desnecessário esse contexto, porém, estabelecer um critério histórico-cultural em que valorizasse fatores de formação de povos, além de fatores naturais para estudar os continentes, sem descartar a importância da Europa e Ásia nesse processo de formação, é uma forma pertinente de abordagem dos conteúdos, podendo ser utilizado e contextualizado de diversos e outros modos, sem a necessidade de tematizar os assuntos, incorporando-se a África em temas já trazidos nos livros didáticos.

Outros exemplos de conteúdos podem ser contextualizados com o ensino das relações étnico-raciais em diversas disciplinas, porém é relevante refletir de que forma esses contextos podem ser utilizados sem que se repitam estratégias dos colonizadores. As imposições de falas e de verdades absolutas não proporcionam o alcance de entendimento que se quer.

Sinalizamos, assim, a importância de o/a professor/a se fazer parte desse processo de construção de saberes. Isso diz respeito às verdades que estabelecemos no mundo social, às veracidades que têm relação com as subjetividades e como enxergamos tais conteúdos. Relacionar os conteúdos em sala de aula com o ensino das relações étnico-raciais é descolonizar-se, resgatando nossas histórias individuais. Se não sabemos quem somos, como iremos entender o outro? O que está sendo ensinado aos professores e professoras nas academias? O que é oferecido como construção de saber a uma 
classe tão subalternizada socialmente como é a do/a professor/a no Brasil, em seus vários contextos? Como desapegar-se de conhecimentos eurocentrados se sempre lhes foi negado reconhecer-se fora deles?

Essas inquietações relacionam-se aos desafios de instituição da lei no 10.639/2003 e dizem respeito às afirmações de identidades por intermédio de ser e estar no mundo. Um dos passos para superação dessa dominação epistemológica está na conscientização de que o outro existe em sua diversidade e que o ponto de partida está no reconhecimento e na aceitação por meio do diálogo.

Paulo Freire (2015) reafirma os ensinamentos que vivenciou na África, pois o encontro e entendimento com o outro lá existentes demonstraram-Ihe os conhecimentos ontológicos de percepção do mundo, e que aparecem em sua obra e na teoria dialógica proposta em sua literatura a serviço da valorização dos saberes populares. O grande respeito que se tem aos mais velhos e aos ancestrais, na tentativa de preservação da cultura, o respeito ao outro e a seus laços familiares, são práticas vivenciadas em países africanos. $\mathrm{O}$ autor defende ainda que, para avançarmos nesse sentido, a luta precisa ganhar unidade e que não há emancipação, de si e do outro, sem uma unidade na diversidade. Reconhecer que as minorias são maioria é um caminho que passa por assumir as semelhanças entre si, e não somente as diferenças, criando a unidade.

$\mathrm{O}$ amadurecimento das ideias também diz respeito à identidade individual, referindo-se à desconstrução de falas, às imposições de valores, de ideais de lutas não contextualizadas sobre oprimir e excluir o outro. A sala de aula é espaço de desconstrução e construção de conhecimento. Dessa forma, é o espaço capaz de atingir transformação social, desde que haja diálogos democráticos que alcancem o consenso e o reconhecimento do que se diz. Assim, consoante Carneiro e Sá (2007), a produção e a reprodução do espaço devem ser pensadas em termos da adoção e mobilização da razão e das ações comunicativas pelas pessoas, enquanto formas de contrarracionalidade e contrafinalidades aos processos de colonização do mundo da vida pelo mundo do sistema.

\section{CONSIDERAÇÕES FINAIS}

A colonialidade do saber trata da forma como se caracteriza a hegemonia do saber eurocêntrico no mundo. Neste artigo, esta é abordada como uma tentativa de meIhor compreender estratégias de dominação que, arraigadas em nosso cotidiano, nos aprisionam e, por vezes, nos impedem de reconhecer saberes outros, inferiorizando-os e/ou negativando-os.

Dessa forma, os desafios de instituição da lei no 10.639/2003 tem relação direta tanto com a desvalorização do que é atribuído ao negro quanto ao processo de monoculturação que se estabeleceu no mundo, implicando racismo estrutural no Brasil e não reconhecimento de si e do outro.

Entende-se que compreender a história individual como forma motivadora para desenvolver projetos inclusivos e de reconhecimento étnico-racial nas escolas não só é visto como uma possibilidade de estabelecimento da lei $n=10.639 / 2003$, mas também para inserir alunos/as em um contexto histórico e cultural que lhes é negado enquanto indivíduos. 
Reconhecer e valorizar outras epistemologias é o ponto de partida para pensar na execução da referida lei. Reconhecer as múltiplas identidades em sua diversidade é uma forma de visualizar realidades e contextos muitas vezes excludentes, trazidos nos conteúdos em sala de aula.

\section{REFERÊNCIAS}

ADAS, Melhem; ADAS, Sergio. Expedições geográficas. São Paulo: Moderna, 2015.

ANDRADE, Manuel Correia de. O Brasil e a África. São Paulo: Contexto, 1996.

BERNADINO-COSTA, José; GROSFOGUEL, Ramón. Decolonialidade e perspectiva negra. Revista Sociedade e Estado, vol. 31, n. 1, jan./abr. 2016.

BRASIL. Lei no 10.639 de 9 de janeiro de 2003. Diretrizes Curriculares Nacionais para a Educação das Relações Étnicos-Raciais e para o Ensino de História e Cultura Afro-Brasileira e Africana. Brasília, DF: Ministério da Educação, 2003.

CARNEIRO, Rosalvo Nobre; PINTO, Francisco Ringostar. Meio técnico-científico-informacional e comunicacional e ensino de geografia. In: COLÓQUIO BRASILEIRO EDUCAÇÃO NA SOCIEDADE CONTEMPORÂNEA, 3., 2012, Campina Grande. Anais [...]. Campina Grande: UFCG, 2012. p. 1-9. Ano III, v. 1, n. 1.

CARNEIRO, Rosalvo Nobre; SÁ, Alcindo José de. A produção social pública dos lugares numa perspectiva comunicativa como contraponto à produção social privada. In: SÁ, Alcindo José de (org.) Por uma Geografia sem cárceres públicos ou privados. Recife: UFPE, 2007. p. 324-335.

FAZENDA, Ivani. Integração e interdisciplinaridade no ensino brasileiro - efetividade ou ideologia. 6. ed. São Paulo: Edições Loyola, 2011.

FREIRE, Paulo. Pedagogia da esperança: um reencontro com pedagogia do oprimido. São Paulo: Paz e Terra, 2015.

FREITAG, Barbara. Dialogando com Jürgen Habermas. Rio de Janeiro: Tempo Brasileiro, 2005.

HABERMAS, Jürgen. Teoria do agir comunicativo: racionalidade da ação e racionalização social. São Paulo: Martins Fontes, 2012a. V. 1.

HABERMAS, Jürgen. Teoria do agir comunicativo: sobre a crítica da razão funcionalista. São Paulo: Martins Fontes, 2012b. V. 2.

HABERMAS, Jürgen. Técnica e ciências como ideologia. Lisboa: Edições 70, 2009.

HABERMAS, Jürgen. Para uma reconstrução do materialismo histórico. 2. ed. São Paulo: Editora Brasiliense, 1990.

HABERMAS, Jürgen. Consciência moral e agir comunicativo. Tradução Guido A. de Almeida. Rio de Janeiro: Tempo Brasileiro, 1989.

MACHADO, Adilbenia Freire. Ancestralidade e encantamento como inspirações formativas: filosofia africana mediando a história e Cultura africana e afro-brasileira. 2014, 240f. Dissertação (Mestrado) - Universidade Federal da Bahia. Faculdade de Educação, Salvador, 2014.

MUNANGA, Kabengele. Superando o racismo na escola. 2. ed. rev. Brasília: Ministério da Educação; Secretaria de Educação Continuada, Alfabetização e Diversidade, 2005.

OLIVEIRA, Eduardo. Epistemologia da Ancestralidade. Entre Lugares: Revista de Sociopoética e Abordagens Afins, v. 1, p. 1-10, 2009.

OLIVEIRA, Luiz Fernandes de; CANDAU, Vera Maria Ferrão. Pedagogia decolonial e educação antirracista e intercultural no Brasil. Educ. Rev., Belo Horizonte, v. 26, n. 1, p. 15-40, abr. 2010. Disponível em: http:// www.scielo.br/scielo.php?script=sci_arttext\&pid=S0102-46982010000100002\&lng=pt\&nrm=iso. Acesso em: 9 abr. 2019. http://dx.doi.org/10.1590/S0102-46982010000100002.

PETIT, Sandra Haydée. Pretagogia: pertencimento, corpo-dança afroancestral e tradição oral: contribuições do legado africano para a implementação da Lei 10.639/03. Fortaleza: Ed. Uece, 2015.

PETIT, Sandra Haydée; FARIAS, Maria Kellynia. Pretagogia, pertencimento afro e os marcadores de africanidades: conexões entre corpos e árvores afroancestrais. In: MACHADO, Adilbenia Freire; FARIAS, Maria Kellynia; PETIT, Sandra Haydée (org.). Memórias de Baobá II. Fortaleza: Imprece, 2015.

PIMENTA, Jose Ramiro; SARMENTO, João; AZEVEDO, Ana Francisca. As geografias pós-colonais. In: PIMENTA, Jose Ramiro; SARMENTO, João; AZEVEDO, Ana Francisca (coord.). Geografia pós-coloniais: ensaios de geografia cultural. Portugal: Figueirinhas, 2007. p. 11-30.

QUIJANO, Anibal. Colonialismo do poder, Eurocentrismo e América Latina. Buenos Aires: Clacso - Consejo Latinoamericano de Ciencias Sociales, 2005. 


\section{\&Educaçắo}

Joyce de Sena Lima-Rosalvo Nobre Carneiro

SANTOS, Milton. Por uma outra globalização: do pensamento único à consciência universal. 11. ed. Rio de Janeiro: Editora Record, 2004.

SANTOS, Milton. O país distorcido: o Brasil, a globalização e a cidadania. Organização Vagner Costa Ribeiro. São Paulo: Publifolha, 2002.

SARAIVA, Adriana. População chega a 205,5 milhões, com menos brancos e mais pardos e pretos. Brasília: Agência IBGE notícias. 24/11/2017. Disponível em: https://agenciadenoticias.ibge.gov.br/agencia-noticias/2012-agencia-de-noticias/noticias/18282-pnad-c-moradores. Acesso em: 18 jan. 2019.

SIEBENEICHLER, Flávio Beno. Jürgen Habermas: razão comunicativa e emancipação. Rio de Janeiro: Tempo Brasileiro, 2003.

WALSH, Catherine. Intercuturalidade crítica e pedagogia decolonial: in-surgir, re-surgir e re-viver. In: CANDAU, Vera Maria (org.). Educação intercultural na América Latina: entre concepções, tensões e propostas. Rio de Janeiro: 7 Letras, 2009. 